\title{
Optimal Voltage Compensation of Small Hydropower Grid Linked Structure Centered on PV-STATCOM Smart Inverter
}

\author{
Adel Elgammal and Tagore Ramlal
}

\begin{abstract}
Alternative renewable energy structures for example hydro turbine generators can be utilised to replace or rise in the efficiency of energy distribution infrastructure in remote communities. A small hydro turbine linked to grid divides the load into current and electricity. The voltage amplitude in the energy distribution structure will be changed as a result of the power quality problem, and this will have a direct influence on the electric load. This study introduces the PV-STATCOM, a novel smart inverter that can be used to control a solar inverter as dynamic reactive power compensator (DRPC). The recommended photovoltaic STATCOM can be utilised to offer voltage regulate for serious structure demands. For the night, the whole inverter capacity is utilised for STATCOM operations. The smart inverter temporarily disables its real power generating function during a large system outage throughout the day and makes its whole inverter capacity accessible for STATCOM operation. This research examines the stability of the voltage control structure's excitation in the Micro Hydro Power Plant. The MOPSO algorithm may be used to regulate the Permanent Magnet Synchronous Machine and control the voltage on the direct current linked part of system. The system will most probably be unstable if the exact definition of system parameters is uncertain. To present the parameter specifications for the stable structure, the DC-link control system is modelled, theoretically assessed, and simulated. This paper proposes the use of a particle swarm optimization centred SVC controller for reactive power optimization and adjustment in a separated hybrid system with micro hydro and wind diesel. The small linear signal model of the hybrid micro hydro Diesel wind model is investigated under various loading scenarios. The SVC controller is compared to the GA-based controller and optimised using the PSO approach. The purpose of study is to employ STATCOM for reactive power compensation in order to increase energy structure's dependable operating limit. It also tries to reduce voltage variations caused by renewable energy sources' variable nature. To obtain an acceptable outcome, the proper modification of Proportional-Integral parameters in STATCOM is conducted consequentially centred on BFA and GA. The STATCOM control circuit's PI controller's settings have been optimised. This article discusses the optimization and adjustment strategies for PID controllers in a STATCOM based circuit for PV-Micro hydro hybrid system voltage stability.
\end{abstract}

\footnotetext{
Submitted on August 31, 2021

Published on September 21, 2021.

Adel Elgammal, The University of Trinidad and Tobago UTT, Utilities Engineering, Point Lisas Campus, Trinidad and Tobago (corresponding e-mail: adel.elgammal $@$ utt.edu.tt)

Tagore Ramlal, The University of Trinidad and Tobago UTT, Utilities Engineering, Point Lisas Campus, Trinidad and Tobago

(e-mail: tagore.ramlal@utt.edu.tt)
}

Keywords - Photovoltaic (PV) solar system, self-tuning fuzzy control, Small Hydro Turbine Generator, smart inverter, STATCOM, voltage control, voltage stability.

\section{INTRODUCTION}

Hydro turbine generators are one of the alternatives RE resources that may be utilised to replace or increase the efficiency of current power supply sources in distant communities. Hydroelectricity is one of most wellestablished type of RE, accounting for about $19 \%$ of worldwide electricity output from small and large power plants [1]. Small hydro turbine generators, which are small hydropower systems, are one of the primary resources being investigated. The small hydro generator, as tool that collects hydro power, must function under particular circumstances [2]. Turbine generators, for example, should have been stabilised. As a result, the generator's voltage and current should stay constant when linked to the grid. At present, voltage sag is most significant power quality issue observed due to its negative financial impact on customers [3]. Major development is being made in exploitation of RES in order to fulfil growing worldwide power demand while simultaneously minimising the impact of unsustainable fossil-fuel extraction on climate change and global warming [4]-[6]. RES including hydro, wind, and geothermal, which account for a significant portion of total installed generation capacity, have witnessed tremendous progress in the deployment, development, and design of RE systems across the world. Furthermore, concerns in developing nations about inadequate and inconsistent power supply have driven greater efforts to maximise the usage of renewable energy resources. As a result, RES such as geothermal, hydropower, solar, and wind energy have piqued international attention [7]-[9]. Power quality and Voltage stability concerns are the key issues restraining the degree of RE penetration in transmission networks [10]. Voltage stability emerges as the most pressing issue. When the prevalence of renewable energy systems increases significantly, this problem is solved [11]. In/ order to ensure economic sustainability and technological feasibility, auxiliary services such as voltage stability measures and reactive power supply must be in place. These auxiliary services are useful for the effective operation and integration of variable renewable energy production [12]. FACT System devices are commonly used to boost energy quality and improve energy structure stability. Flexible AC Transmission System devices are accessible in variety of sizes and forms, each with its own set of competencies, advantages, and disadvantages [13]. With varying degrees of 
efficacy, a Flexible AC transmission device can be utilized alone or in combination with an additional Flexible AC Transmission System device type to regulate transmission structure characteristics that are important to grid correct functioning and the improvement of grid power quality and voltage stability. In [14], voltage stability is characterised as a power structure's capacity to sustain constant voltages across all buses despite being disturbed from a particular initial operational condition. Following a system interruption, voltage instability occurs when a power structure fails to keep consistent voltages at its buses. Voltage unbalance is a major problem in energy systems due to insufficient reactive power maintenance to keep bus voltages between normal ranges. When it refers to severely overloaded energy structures or rising system demands, voltage stability is a major issue. Voltage uncertainty in energy system can also be caused by faults at particular points within the network or at the network level. If voltage unbalance arises at the network level and no rapid maintenance steps are taken, the grid may partially or completely collapse. A lot of studies using STATCOM have been conducted in recent years. A hybrid wind-photovoltaic supply structure with STATCOM interface was investigated for a water-lift station. The voltage instability was brought down to a manageable level [5]. The work has looked at the stabilization effect of Flexible AC transmission devices on energy systems linked to doubly fed induction wind generators, with an emphasis on rotor angle response. [6]. A control methodology for STATCOM based on VSC that uses both direct and conventional current vector control methods has been described. However, it just operated on the system's voltage fluctuations, and they didn't have to cope with a hybrid system [7]. In a hybrid power structure centred on a wind energy conversion system, voltage management using reactive power assistance has been described in [8]. However, STATCOM was not used to decrease voltage fluctuations using the load side converter in this study. According to the literature assessment, there has been very limited study on the voltage fluctuations based STATCOM system produced by the hybrid windsolar microgrid. Traditional Flexible AC Transmission System devices still require controller changes and extensive testing under a range of operating conditions, despite the growing installation of wind and PV power structures. The optimum gain of STATCOM was adjusted in [9] to do dynamic study of hybrid energy structures. In another work, GA is used to concurrently conclude Proportional-Integral control parameters of Automatic Voltage Regulator and Static Var Compensator in a control structure involving AVR and SVC [10]. For the separated hybrid power system model, a searcher optimization technique was used. [11] Provided a performance investigation utilising a TakagiSugeno type fuzzy logic based controller. Throughout the night, a new technique of using photovoltaic solar farms as STATCOM for various grid support tasks was suggested. It gave the same benefits throughout the day, with inverter capacity remaining after real power generation [22], [23]. STATCOM is a VSC based FACTS device [24]. It can offer rated reactive current and dynamic reactive power correction at voltages as low as $0.2 \mathrm{pu}$ with a reaction time of 1-2 cycles. Photovoltaic STATCOM, or using a photovoltaic solar farm as a STATCOM, has been proven to improve the connectivity of adjacent wind farms [25], [26], as well as boost energy transmission capability at dark and during the day [25]-[27]. The controller design of a VSC centred Distribution STATCOM on an RTDS and its consequent laboratory operations on a FPGA/DSP platform are described in [25], [28]. A unique approach for using an SPV inverter as a STATCOM is described in [29]. PVSTATCOM is a gadget that can help with power transmission issues both during the day and at night. An authentic single-machine infinite-bus energy structure with photovoltaic STATCOM in the middle was used to conduct transient stability testing. The analysis was carried out using the Electromagnetic Transients with Power System/DC Computer Aided Design programme. The research findings indicated that photovoltaic STATCOM can greatly improve the steady energy transmission limits at daytime and during the night, even with enormous active power production. The usage of photovoltaic STATCOM in combination with damping controls and voltage to enhance transmission line power transmit capability was studied by authors in [30] Harmonic study was also implemented using the photovoltaic STATCOM at the transmission line's center. According to the findings, the photovoltaic STATCOM is useful in improving structure stability by reducing THD under fault situations. [31] also considers if other reactive and active power reduction control approaches for special purpose vehicle plants may be improved. The PSO technique was used to adjust the reactive and real power assist. In the optimization process, rate of change of voltage phase angle, rate of change of voltage, and the rate of change of frequency were all employed. SPV reactive and active power support has a detrimental impact on grid stability following a breakdown, according to modeling studies. This impact can be mitigated by adjusting the SPV parameters based on the PSO. FACTS devices must be ideally selected, scaled, and placed for various practical applications. For efficient performance under changing grid operating circumstances, they must also be appropriately adjusted and managed. Several studies have been conducted in this area. [32] suggests an optimal STATCOM controller for improving the wind incorporated power grid in fault situations. During voltage sag, Particle Swarm Optimization and Ant Colony Optimization techniques were used to get the flexible proportional integral parameter modification needed to improve STATCOM's dynamic behaviour. To improve voltage profile, the PSO technique was utilised to propose TCSC and SVC coordinated parameters in [33]. MATLAB was utilized to evaluate the method on an IEEE 9-bus system. [34] Also used SVC and TCSC to develop multi-objective voltage stability control approach. To regulate voltage in the electrical system, new control algorithms are being designed and used. One of them is MPC. Few researches have looked into the use of Model Predictive Control in power grid voltage stability. Several of these researches concentrate on the use of Model Predictive Control to regulate load [35-38]. The use of neural-based predictive control to regulate FACT devices was studied in [39]. The neural-based predictive control was utilized to control real-time power flow with SSSC and to regulate bus voltages with STATCOM. In terms of control signal quality 
and overshoots, the NPC's design and performance were compared to those of a standard PI controller. The outcomes indicate that NPC may be used to achieve adaptive control in a power structure. [40] Has done a comparison study of Model Predictive Controller and Deadbeat Controller for power quality enhancement in Distribution-STATCOM (DSTATCOM). In order to acquire the necessary load current value, the system's state-space model was employed in a deadbeat predictive algorithm to calculate requisite current reference value. In Model Predictive Controller, a discrete-time model of the system was used to predict future current behaviour for each potential voltage vector acquired from the Distribution-STATCOM. A voltage vector was designed and applied that minimised a cost function. The efficacy of the two controllers was investigated using a MATLAB-Simulink model. The controllers have been demonstrated to increase DSTATCOM's performance in terms of voltage management, harmonic abatement, power factor correction, and load balancing, addressing power quality concerns. For UPFC control, [41] recommended building a Multiple Output Multiple Input Nonlinear Optimal Predictive Control structure. The dynamic voltage models of the DC connection as well as the dq mathematical models of the series and shunt UPFC components were used to execute this control approach Simulations in the EMTDC/PSCAD software environment were done using a one-machine, two-line infinite-bus network with UPFC added to test the robustness of the proposed method. In terms of system tracking behaviour and closed loop stability, the control method outperformed the typical proportional integral controller. In [42], a similar NLOPC technique was used to STATCOM. Low frequency oscillations can be efficiently dampened by NLOPC, and transient stability can be maintained. According to simulation studies, it also improves the dynamic performance of an energy structure equipped with STATCOM. These tests, however, were unable to convincingly show the NLOPC system's utility in enhancing RE-integrated grid voltage stability under variety of grid operating situations. Furthermore, the study only looked at single-machine, double-line infinite bus structures. As a result, additional study is required to provide useful information for a real-world energy system application.

The PV-STATCOM smart inverter described in this work may be used to operate a solar inverter like a reactive current compensator. During essential system demands, the suggested photovoltaic STATCOM can be used to provide voltage control. The entire inverter capability is used for STATCOM activities at night. The smart inverter momentarily ceases generating real electricity and releases all of its inverter capacity for STATCOM operation throughout a severe network interruption during the day. The stability of the excitation voltage control system in a Micro Hydro energy Plant is investigated in this study. Using the MOPSO algorithm to regulate the Permanent Magnet Synchronous Machine, the voltage on the direct current linked component of the system may be controlled. The system will most likely be unstable if the accurate description of system components is unclear. To get a reliable system parameter specification, the direct current linked control system is modelled, simulated, and scientifically assessed.

\section{HYBRID WIND/PV/FC/BESS COORDINATED WITH HYDROELECTRIC POWER PLANT POWER SYSTEM CONFIGURATION}

Micro Hydro Power Plants have become the most widely used power production methods worldwide. This sort of power plant has a lot of promise, especially in countries with a lot of rivers. On a Micro Hydro Power Plant, Doubly Fed Induction Generator and PMSG may be utilised to produce an independent system. A direct drive PMSG design is commonly utilised in variable speed hydraulic systems for the following reasons: Due to its great efficiency and power density, a PMSG offers exceptional electric driven capabilities. Grid interruptions are also less of an issue because the converter decouples the generator from the grid. PMSGs with complete power converters also have a wider range of speed control. Figure 1 depicts a variable speed grid-connected MHPGS. A Propeller, Kaplan, or Bulb micro-hydraulic turbine, a PMSG, and two consecutive voltage source converters with PWM interface with the three-phase grid make up the system. Voltage, current, and position sensors, among other auxiliary devices, are also shown. The power converter was used to send both reactive and active energy to the grid system. The suggested method is utilised to safeguard sensitive electrical loads from power system disruptions, such as auto switches in power electronics, big semiconductors and so on. The three-level diode-clamped converter, DC voltage source, control system and are the primary components of an SVC. A photovoltaic (PV) system is included in the proposed SVC architecture to serve as a DC power source. PV is beneficial since it does not produce noise, hazardous pollutants, or toxic gases, does not require direct sunlight to work, and does not consume any fuel. This type of modular photovoltaic system has no moving parts to wear out or fail and may be promptly installed anywhere, needs slight maintenance. The electric power generated by the photovoltaic structure has been determined to be economically viable. The SVC's output signal is routed via an LC filter, which attenuates it and removes harmonics in the distribution system. When the control systems were first turned on, there was voltage sag. It will be verified by Detector. The reference voltage generator component creates a reference voltage for comparison with the real voltage in the system when there are indicators of it. In the compensatory voltage injection \& voltage generator portion, the voltage from the comparison is transformed to PWM. This drives the converter and injects voltage into the system. Figure 1 depicts a system that may be split into two separate control systems. The first system controls MSC to regulate the stator voltage to load, while the second system controls GSC to adjust the excitation voltage. The regulation of excitation voltage on the system is the subject of this article. As a result, the second system is mostly employed for the purposes of the analysis that will be carried out in this study. A stability issue develops in the excitation voltage control structure when elements such as load resistance, voltage reference, and water velocity so on are not used to their full potential. For example, when a simulation is run with random values for the above parameters, the excitation voltage (DC-link voltage) is the outcome. It has been observed that using an incorrect value for some parameters might result in an 
unstable system situation. To fully understand this issue, a thorough examination of the control problem is required. To determine the precise value of those parameters, the system is modelled, then simulated and quantitatively evaluated. The parameter value necessary to produce a stable system may be determined using this technique. The mathematical link between the optimised parameters is known as the objective function. In this challenge, Particle swarm optimization is used as an optimization strategy to optimise the objective function. The optimization of the goal function dampens the fluctuations of the Static Var Compensator controller by maximising the damping ratio of the SVC controller's weakly damped eigen values. The hybrid system's stability margin improves as a result of this procedure, and improved damping is obtained with a little increase in terminal voltage. By lowering rising time (tr), settling time (ts), overshoot $(\mathrm{Mp})$ of the terminal voltage and the steady state error (Ess) performance index optimization improves the hybrid system's stability margin. The performance index is calculated using integral square time error (ISTE), integral square error (ISE), and integral absolute error (IAE). The MOPSO optimization approach is used to adjust the PI type controllers, which are then compared to MOGA. In both MOGA and MOPSO optimization, the objective function is well-defined using ITAE. A MATLAB-based simulation utilising a MOPSO centred Static Var Compensator Controller for the micro hydro hybrid energy structure was used to observe the peak overshoots and settling points of key considerations of the hybrid structure. The voltage stability and reactive power of the hybrid energy structure have improved with a $20 \%$ step load variation. Traditional PID controllers and MOPSObased SVC controllers detect variations in all system parameters under system uncertainty. The hybrid power system's stability is investigated. The objective function ITAE is used in this study, and the performance criteria for optimization is named ' $\mathrm{J}$ '.

$$
J=\int_{0}^{T} \mid \text { Error } \mid t d t
$$

$\mathrm{T}$ is generally selected to be larger than the settling period during which the integral approaches steady state value. In the STATCOM's control circuit, the sum of the errors is specified as the target function.

$$
\begin{aligned}
J_{1} & =\int_{0}^{T}\left|V_{D C}^{r e f}-V_{D C}^{m e s}\right| t d t \\
J_{2} & =\int_{0}^{T}\left|V_{A C}^{r e f}-V_{A C}^{m e s}\right| t d t \\
J_{3} & =\int_{0}^{T}\left|I_{q}^{r e f}-I_{q}^{m e s}\right| t d t \\
J_{4} & =\int_{0}^{T}\left|I_{d}^{r e f}-I_{d}^{m e s}\right| t d t
\end{aligned}
$$

$S O F=\alpha_{1} J_{1}+\alpha_{2} J_{2}+\alpha_{3} J_{3}+\alpha_{4} J_{4}$

The STATCOM control circuit is designed as illustrated in Fig. 1 for controlling current controller (Id, Iq), AC voltage controller, DC voltage controller, and optimization using a set of multi-objective functions. The total error value is determined using the integral time absolute error formulation in Simulink, and then the ITAE formulation is used to optimise it. A good optimization with the population size, mutation, multiplication, and correct restriction values has been carried out, and BFA and GA codes acceptable with the m-function file have been created. In MATLAB, the $\mathrm{m}$-function file optimises eight variables in an eightdimensional search space, with $\mathrm{Ki}$ and $\mathrm{Kp}$ values set to particular lower and higher boundaries.

\section{SimUlation RESUlTS AND DISCUSSIONS}

MATLAB/Simulink is the simulation software. The PVSTATCOM and small hydro generator is linked to a transmission line, as presented in Fig. 1. Each phase of the PV-STATCOM is comprised of 3 level diode clamped converter with eight switches. $30 \mathrm{kHz}$ is the switching frequency. We also apply an AC filter at the PV-STATCOM output to remove switching harmonics. In this example, instead of batteries, we used PV to power the DC connection that is linked to the DC capacitor. $30 \mathrm{~kW}, 220 \mathrm{~V} 3$ phase, $60 \mathrm{~Hz}$ back-to-back converter and PMSG coupled to grid side of the tiny hydro turbine generator utilized in this scenario. As part of the simulation technique used in this work, the controller constant, resistive load, DC voltage reference, and water velocity were all changed. By changing one of the parameters intact while leaving the others as an independent variable, variation may be created. The system is simulated in Matlab, and outcomes are analyzed both visually and analytically. At intervals of 0.1 to $0.2 \mathrm{~s}$, it is applied to the network. We utilized a three-phase ground fault to cause a disruption in the system, which was employed to system between 0.1 and $0.2 \mathrm{~s}$. The simulation starts with a tiny hydro turbine generator that is linked to the grid and has duration of 0.1 to $0.2 \mathrm{~s}$. The voltage of small hydro generator and supply after they have been synchronized to the grid is shown in Fig. 2-6. Input to the load depicted in Fig. 7-10 is divided by current and supply power, along with small hydro turbine generator. The network voltage sags between 0.1 and $0.2 \mathrm{~s}$ after a defect is applied in the network, as illustrated in Fig. 11 and 12. Fig. 13 and 14 illustrate how supply power and small hydro turbine generators are diminishing. PV-STATCOM is a device that injects voltage into the network. Fig. 15 and 16 depict the PV-injection STATCOM's voltage and power, respectively. Load voltage, current, and power stay constant during the application of a fault in the network, as shown in Fig. 17 and 18. According to the findings, the system can tolerate a given range of direct current voltage reference. The system will be unstable if the direct current voltage reference value is not between 1 and $0.2 \mathrm{~V}$. When high water velocity occurs, the results demonstrate that the system tends to be stable. The system might become unstable if the water velocity is too low. The issue can be 
settled by lowering the supplied reference voltage. The findings show that if load resistance is low, the structure is prone to instability. The system is comparatively stable when a substantial load resistance is utilised. The findings show that if the controller constant is kept within an acceptable range, system stability is unaffected. Only the system response characteristics are affected by controller constants.
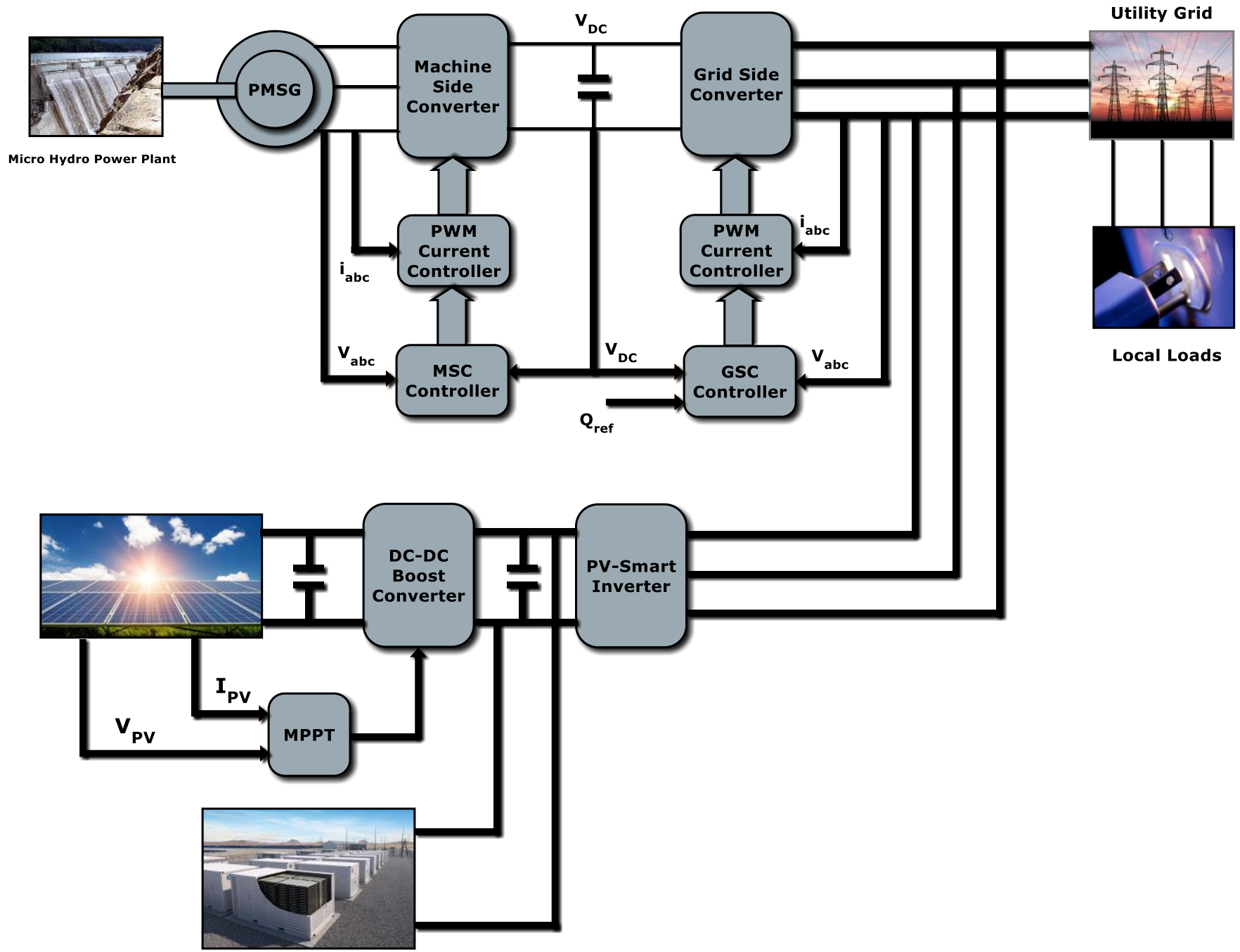

Battery Storage System

Fig. 1. Modelling of the proposed system and control of smart PV inverters.

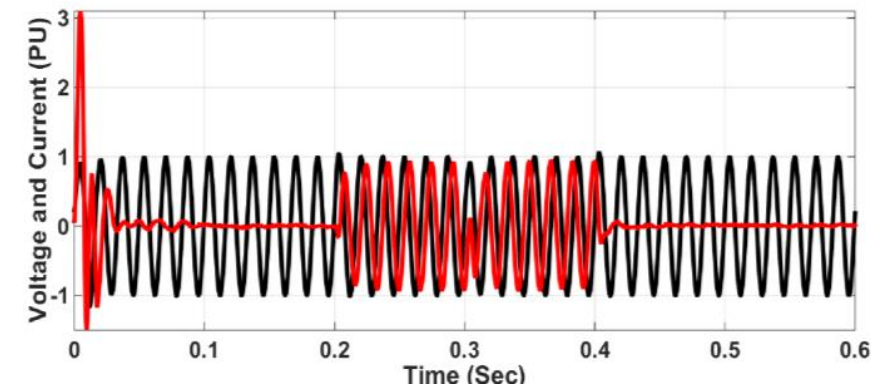

Fig. 2. Generated voltage and current.

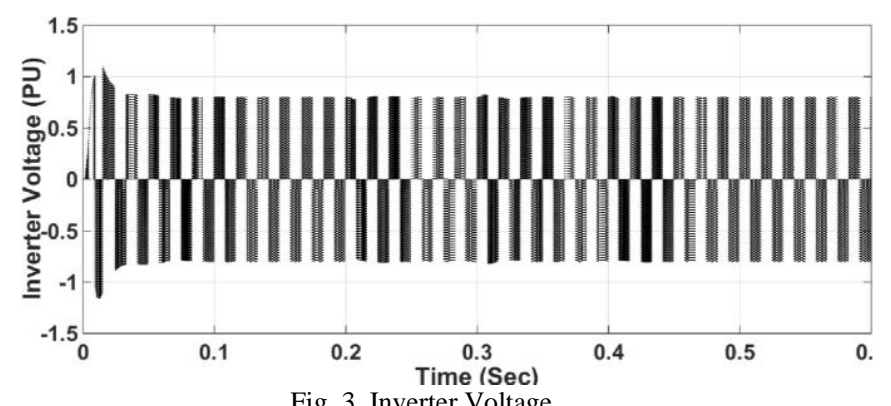

Fig. 3. Inverter Voltage.
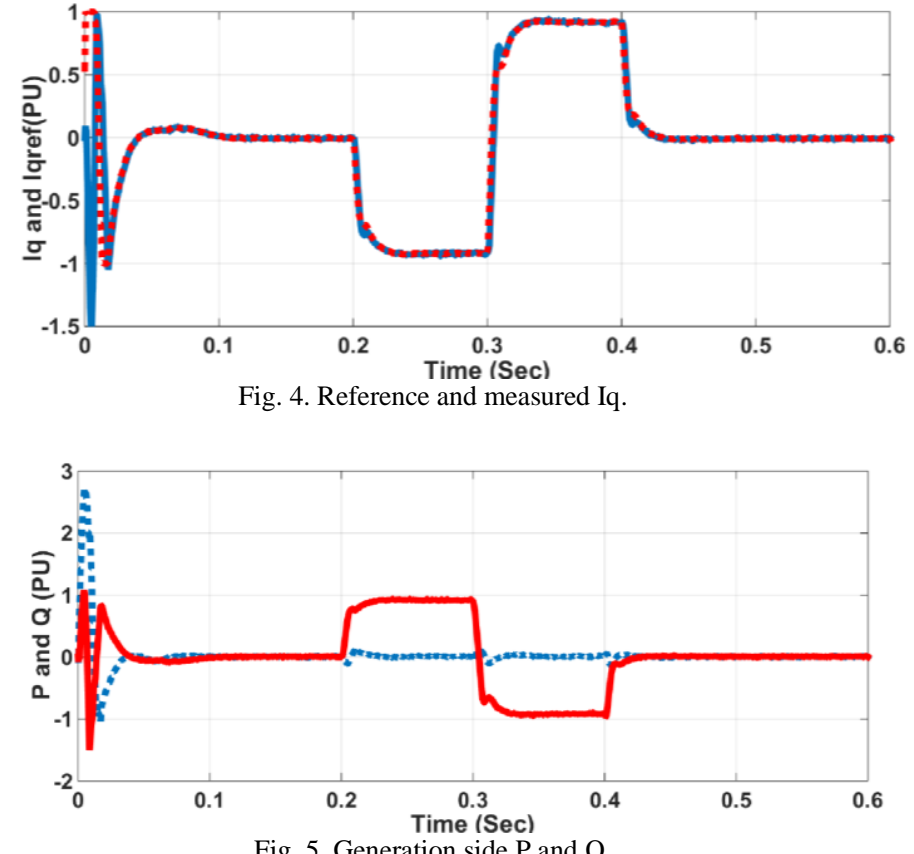

Fig. 5. Generation side $\mathrm{P}$ and $\mathrm{Q}$. 


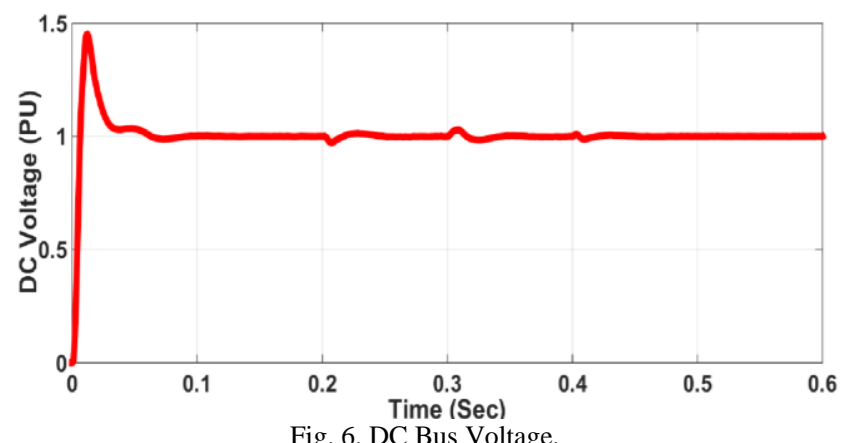

Fig. 6. DC Bus Voltage.

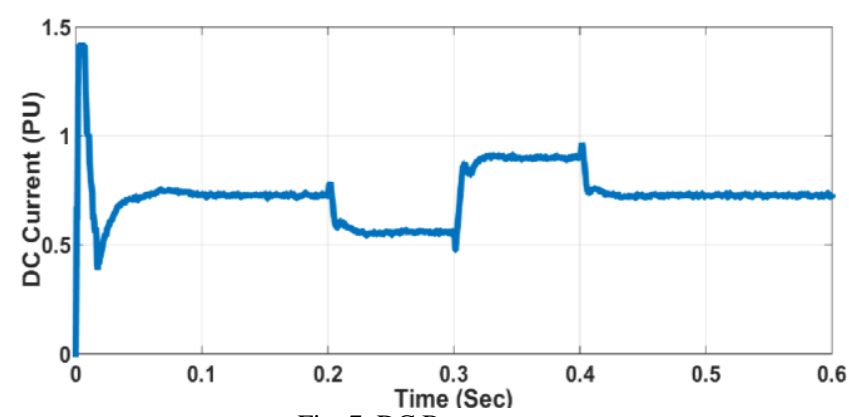

Fig. 7. DC Bus current.

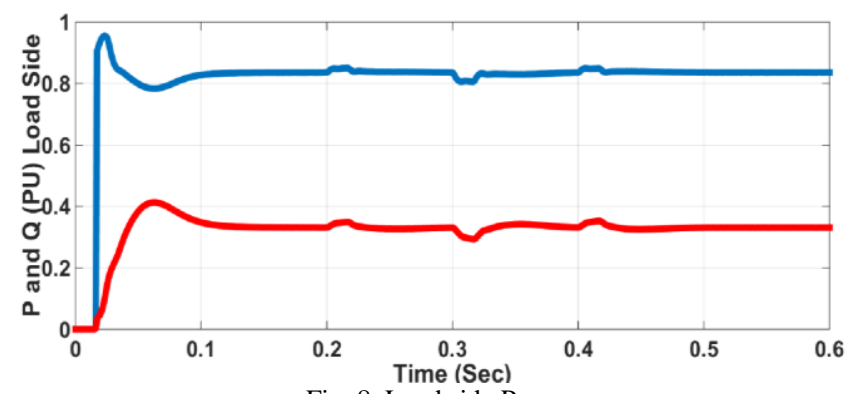

Fig. 8. Load side $\mathrm{P}$ an

d Q.

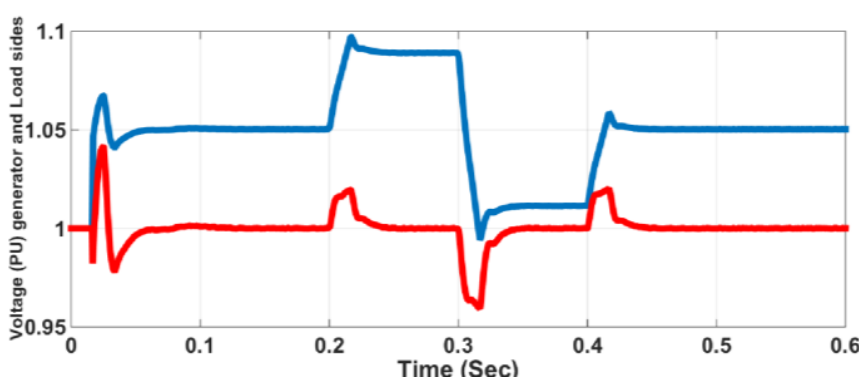

Fig. 9. Magnitude of generated voltage and Load voltage.

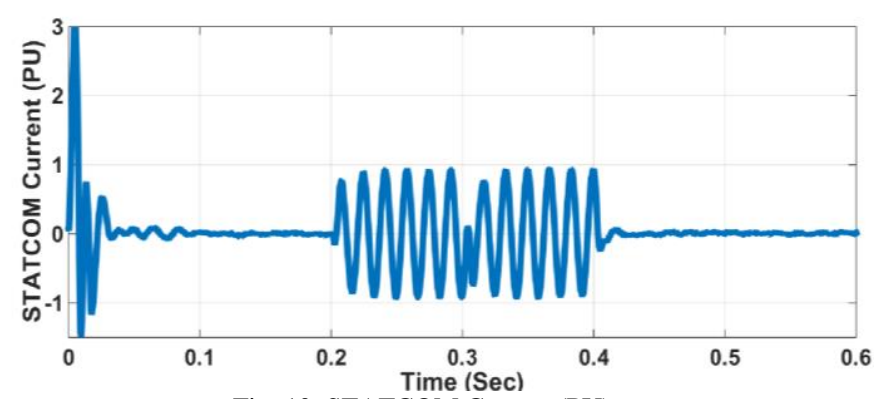

Fig. 10. STATCOM Current (PU)

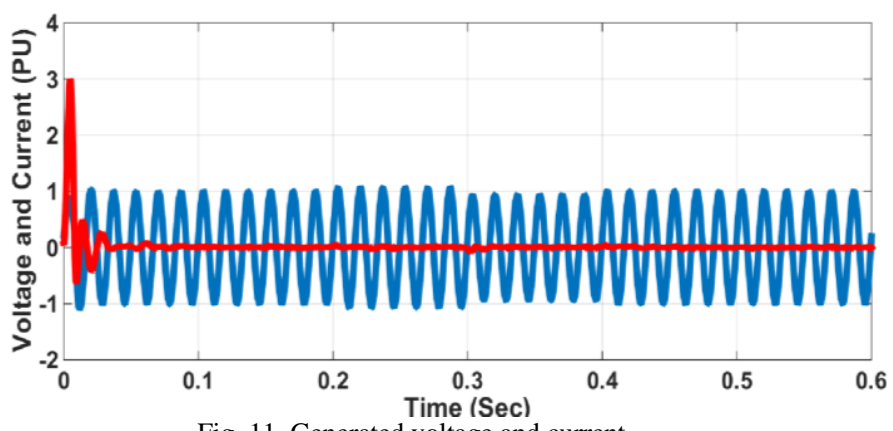

Fig. 11. Generated voltage and current.

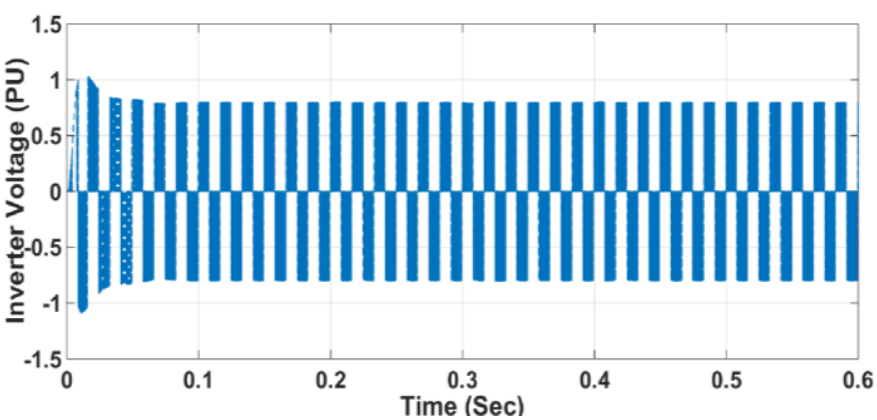

Fig. 12. Inverter Voltage.

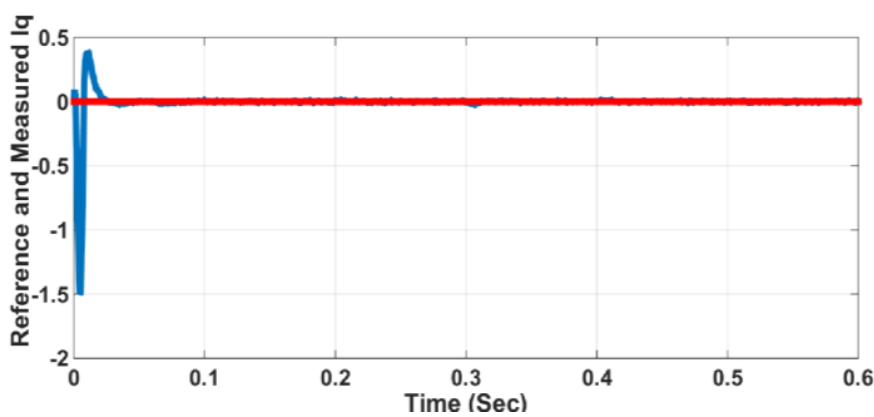

Fig. 13. Reference and measured Iq.

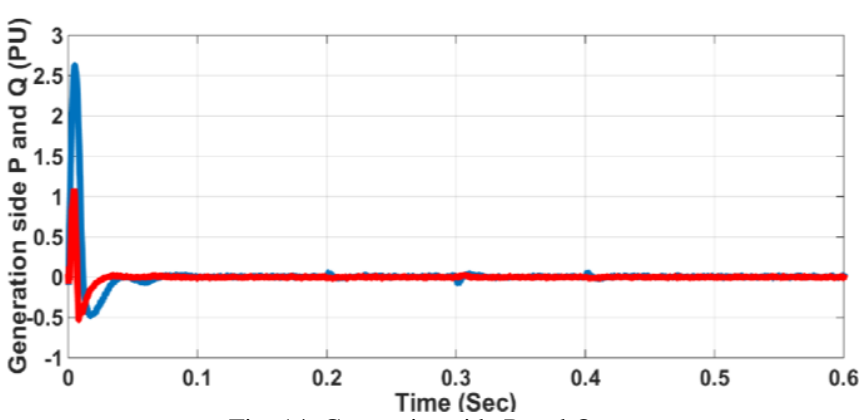

Fig. 14. Generation side P and Q.

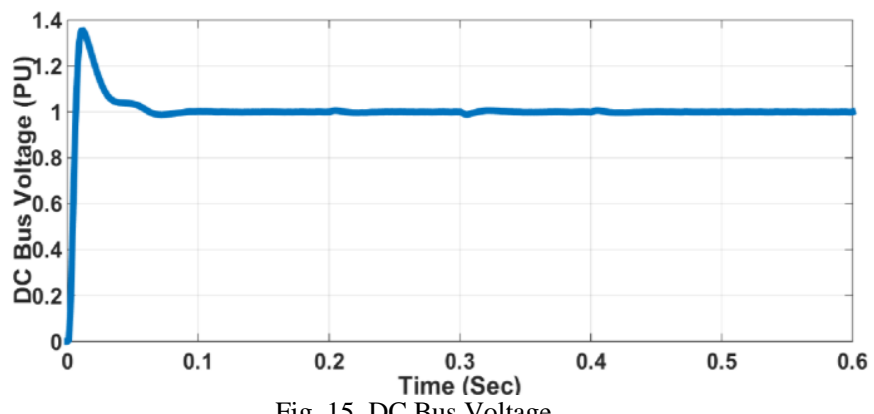

Fig. 15. DC Bus Voltage. 


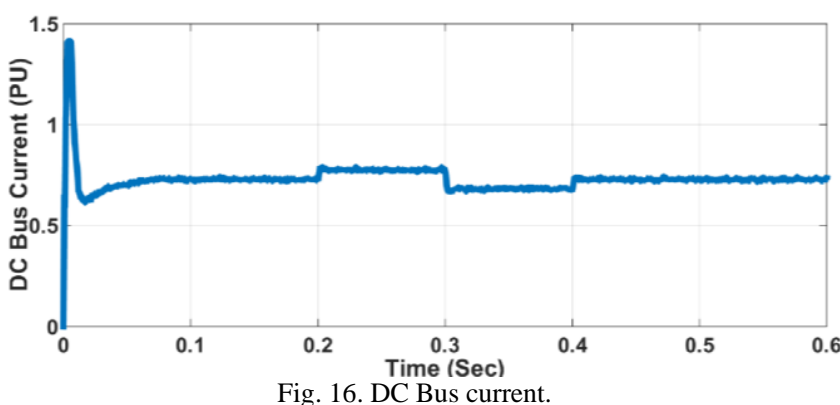

Fig. 16. DC Bus current.

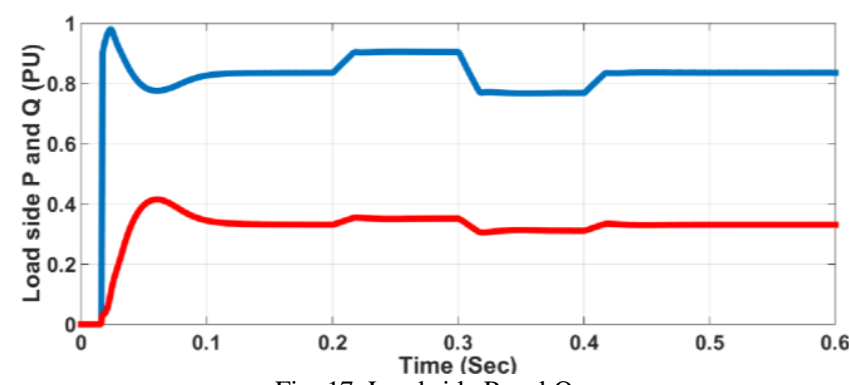

Fig. 17. Load side $\mathrm{P}$ and $\mathrm{Q}$.

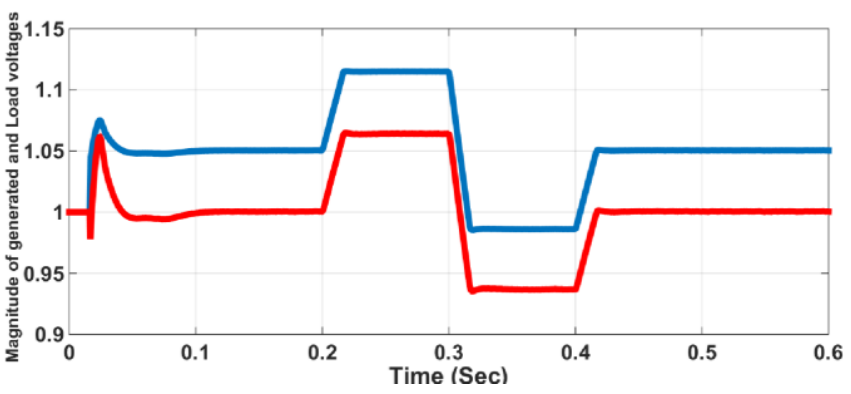

Fig. 18. Magnitude of generated voltage and Load voltage.

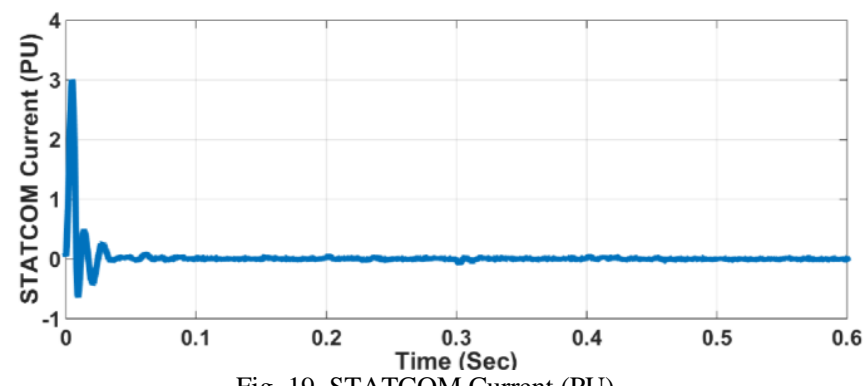

Fig. 19. STATCOM Current (PU).

\section{CONCLUSION}

Hydro energy is recognised the most efficient renewable energy sources because of its huge potential. A variable speed method is recommended to enhance hydraulic power profitability and optimise the hydraulic transient process. The architecture used in this article is a direct drive PMSG. Because it has a wider speed range and better antidisturbance capacity, a direct drive PMSG design is utilised in this investigation. Low load resistance, an out-of-range DC voltage reference, and Low water velocity all contribute to the Autonomous Micro Hydro Plant structure's inability to maintain stability. This study proposes a three-level diode-clamped converter DVR using solar energy and a small hydro turbine generator connected to the grid to improve the power distribution system. The small hydro generator can assist in grid synchronisation, decreasing the quantity of power supplied to the load. This work offers a new technique for reactive power adjustment and transient stability analysis in the diesel-wind-micro hydro hybrid structure by including a Particle swarm optimization based SVC controller. The findings show how the system characteristics vary when the load varies, and it is obvious that models have accomplished reactive energy compensation. The SVC controller based on the PSO algorithm operates optimally, and the whole outcomes increase. The system displays changes in the output and effective improvement by altering the values of $\mathrm{Ki}$ and $\mathrm{KP}$ and, and therefore the system's stability is increased. The PVSTATCOM smart inverter is described in this article, and it may be used to run a solar inverter by means of a dynamic reactive power compensator-STATCOM. During essential system demands, the suggested photovoltaic STATCOM can be used to provide voltage control. The entire inverter capacity is used for STATCOM activities at night. The smart inverter stops generating real electricity and releases all of its inverter capacity for STATCOM operation during a large system outage throughout the day. This study shows new ways to employ PV solar farm inverters at night to improve electricity grids in a variety of ways. It also shown that with inverter capacity left over after actual power generation, the same aims could be achieved throughout the day. PVSTATCOM is a cutting-edge technology that converts the solar farm inverter into a STATCOM. The PVSTATCOM control system is used to significantly raise the power transfer limit of a long transmission line both at night and during the day, even when the solar farm is producing a huge quantity of actual electricity. In addition to selling real power, this method might provide additional cash streams for solar farms.

\section{REFERENCES}

[1] W. Gil-González, A. Garcés and O. B. Fosso, "Passivity-based control for small hydro-power generation with PMSG and VSC," IEEE Access, vol. 8, pp. 153001-153010, 2020, doi: 10.1109/ACCESS.2020.3018027.

[2] T. Holzer, A. Muetze, G. Traxler-Samek, M. Lecker and F. Zerobin, "Generator Design Possibilities for Full-Size Converter Operation of Large Pumped Storage Power Plants," IEEE Transactions on Industry Applications, vol. 56, no. 4, pp. 3644-3655, July-Aug. 2020, doi: 10.1109/TIA.2020.2989074.

[3] B. S. Pali and S. Vadhera, "An innovative continuous power generation system comprising of wind energy along with pumpedhydro storage and open well," IEEE Transactions on Sustainable Energy, vol. 11, no. 1, pp. 145-153, Jan. 2020, doi: 10.1109/TSTE.2018.2886705.

[4] B.B. Adetokun, J.O. Ojo, C.M. Muriithi, Reactive power-voltagebased voltage instability sensitivity indices for power grid with increasing renewable energy penetration, IEEE Access. 8, 2020, pp. 85401-85410

[5] J.V. Ringwood, S. Simani, Overview of modelling and control strategies for wind turbines and wave energy devices: Comparisons and contrasts, Annu. Rev. Contr. 2015, vol. 40, pp. 27-49.

[6] A.S.O. Ogunjuyigbe, T.R. Ayodele, B.B. Adetokun, A.A. Jimoh, Dynamic performance of wind-driven self-excited reluctance generator under varying wind speed and load, in: 2016 IEEE International Conference on Renewable Energy Research and Applications (ICRERA), 2016, pp. 506-511.

[7] T.R. Ayodele, A.S.O. Ogunjuyigbe, B.B. Adetokun, Optimal capacitance selection for a wind-driven self-excited reluctance generator under varying wind speed and load conditions, Appl. Energy, 2017, vol. 190, pp. 339-353. 
[8] A.S.O. Ogunjuyigbe, T.R. Ayodele, B.B. Adetokun, Steady state analysis of wind driven self-excited reluctance generator for isolated applications, Renew. Energy, 2017, vol 114, pp. 984-1004.

[9] A. van der Schaft, T. Stegink, Perspectives in modeling for control of power networks, Annu. Rev. Contr., 2016, vol. 41, pp. 119-132.

[10] Z. Tang, D.J. Hill, T. Liu, Two-stage voltage control of subtransmission networks with high penetration of wind power, Contr. Eng. Pract., 62 (2017/05/01/ 2017), pp. 1-10.

[11] L. Chen, Y. Min, Y. Dai, M. Wang, Stability mechanism and emergency control of power system with wind power integration, IET Renew. Power Gener., 2017, vol. 11, no. 1, pp. 3-9.

[12] M.E. Meral, D. Çelík, A comprehensive survey on control strategies of distributed generation power systems under normal and abnormal conditions, Annu. Rev. Contr., 2019, vol. 47, pp. 112-132.

[13] S. Venkateswarlu, M. Janaki, R. Thirumalaivasan, N. Prabhu, A review on damping of torsional interactions using VSC based FACTS and subsynchronous damping controller, Annu. Rev. Contr., 2018, vol. 46, pp. 251-264.

[14] P. Kundur, et al., Definition and classification of power system stability IEEE/CIGRE joint task force on stability terms and definitions, IEEE Trans. Power Syst., 2004, vol. 19, no. 3, pp. $1387-$ 1401.

[15] D. Menniti, A. Pinnarelli, N. Sorrentino, An hybrid PV-Wind supply system with D-Statcom interface for a water-lift station, International Symposium on Power Electronics, Electrical Drives, Automation and Motion, 2010. DOI:10.1109/SPEEDAM.2010.5545070.

[16] N.S. Kumar, J. Gokulakrishnan, Impact of FACTS controllers on the stability of power systems connected with doubly fed induction generators, Electr. Power Energy Syst., 2011, vol. 33, pp. 1172-1184, https://doi.org/10.1016/j.ijepes.2011.01.031.

[17] S. Li, L. Xu, T.A. Haskew, Control of VSC-based STATCOM using conventional and direct-current vector control strategies, Electr. Power Energy Syst., 2013, vol. 45, pp. 175-186, https://doi.org/10.1016/j.ijepes.2012.08.060.

[18] D.K. Yadav, T.S. Bhatti, Voltage control through reactive power support for WECS based hybrid power system, Electr. Power Energy Syst., 2014, vol. 62, pp. 507-518. https://doi.org/10.1016/j.ijepes.2014.04.067

[19] P. Sharma, T.S. Bhatti, K.S.S.S. Ramakrishna, Control of reactive power of autonomous wind-diesel hybrid power systems, Joint International Conference on Power Electronics, Drives and Energy Systems (PEDES), 2010. DOI: 10.1109/PEDES.2010.5712461.

[20] V. Sitthidet, N. Issarachai, K. Somyot, Coordinated SVC and AVR for robust voltage control in a hybrid wind-diesel system, Energy Convers. Manage. 2010, vol. 51, pp. 2383-2393, https://doi.org/10.1016/j.enconman.2010.05.001.

[21] B. Abhik, V. Mukherjee, S.P. Ghoshal, Modeling and seeker optimization based simulation for intelligent reactive power control of an isolated hybrid power system, Swarm Evol. Comput., 2013, vol. 13, pp. 85-100, https://doi.org/10.1016/j. swevo.2013.05.003.

[22] R. K. Varma, V. Khadkikar, and R. Seethapathy, "Nighttime application of PV solar farm as STATCOM to regulate grid voltage," IEEE Trans.Energy Convers., vol. 24, no. 4, pp. 983-985, Dec. 2009.

[23] R. K. Varma, V. Khadkikar, and S. A. Rahman, "Utilization of distributed generator inverters as STATCOM," PCT Patent application PCT/CA2010/001419, Sep. 15, 2010.

[24] N. G. Hingorani and L. Gyugyi, Understanding FACTS. Piscataway, NJ, USA: IEEE Press, 2000.

[25] E. M. Siavashi, "Smart PV inverter control for distribution systems," Electron. Thesis Dissertation Repository, 3065, 2015. [Online] Available: https://ir.lib.uwo.ca/etd/3065.

[26] R. K. Varma, S. A. Rahman, A. C. Mahendra, R. Seethapathy, and T. Vanderheide, "Novel nighttime application of PV solar farms as STATCOM (PV-STATCOM)," in Proc. IEEE Power Energy Soc. General Meeting, Jul. 2012, pp. 1-8.

[27] R. K. Varma, S. A. Rahman, and T. Vanderheide, "New control of PV solar farm as STATCOM (PV-STATCOM) for increasing grid power transmission limits during night and day," IEEE Trans. Power Delivery, vol. 30, no. 2, pp. 755-763, Apr. 2015.

[28] V. Dinavahi, R. Iravani, and R. Bonert, "Design of a real-time digital simulator for a d-statcom system," IEEE Trans. Ind. Electron., vol. 51, no. 5, pp. 1001-1008, Oct. 2004.

[29] R.K. Varma, S.A. Rahman, T. Vanderheide, New control of PV solar farm as STATCOM (PV-STATCOM) for increasing grid power transmission limits during night and day, IEEE Trans. Power Deliv., 2015, vol. 30. No. 2, pp. 755-763.

[30] R. Nivedha, R.N. Banu, A.O. Prakash, Enhancement of grid power transmission limits using photovoltaic solar farm as STATCOM (PVSTATCOM), in: 2016 International Conference on Computing
Technologies and Intelligent Data Engineering (ICCTIDE'16), 2016, pp. 1-6.

[31] A. Swandaru, M.D. Rotaru, J.K. Sykulski, Intelligence based coordination of large scale grid-connected photovoltaic systems, in: 2016 51st International Universities Power Engineering Conference (UPEC), 2016, pp. 1-6.

[32] G.E. Ahmed, Y.S. Mohmed, O.M. Kamel, Optimal STATCOM controller for enhancing wind farm power system performance under fault conditions, in: 2016 Eighteenth International Middle East Power Systems Conference (MEPCON), 2016, pp. 226-233.

[33] M.C. Pandya, J.G. Jamnani, Coordinated control of SVC and TCSC for voltage profile improvement employing particle swarm optimization, in: 2017 International Conference on Smart Technologies for Smart Nation (SmartTechCon), 2017, pp. 80-84.

[34] F. Zhang, C. Guo, L. Jiang, L. Yang, J. Zhang, The multi-objective voltage stability coordinated control strategy of FACTS, in: 2013 IEEE Power \& Energy Society General Meeting, 2013, pp. 1-5.

[35] T. Amraee, A.M. Ranjbar, R. Feuillet, Adaptive under-voltage load shedding scheme using model predictive control, Elec. Power Syst. Res., 2011, vol. 81, no 7, pp. 1507-1513.

[36] A.M. Ersdal, L. Imsland, K. Uhlen, D. Fabozzi, N.F. Thornhill, Model predictive load-frequency control taking into account imbalance uncertainty, Contr. Eng. Pract., 2016, vol. 53, pp. 139150.

[37] M. Larsson, D.J. Hill, G. Olsson, Emergency voltage control using search and predictive control, Int. J. Electr. Power Energy Syst., 2002, vol. 24, no. 2, pp. 121-130.

[38] I.A. Hiskens, B. Gong, Voltage stability enhancement via model predictive control of load, Intell. Autom. Soft Comput., 2006, vol. 12 no. 1 , pp. $117-124$

[39] R.O. Tapia, P.H. Zuniga, J.M. Ramirez, Neural-based predictive control applied to FACTS devices, in: 2006 38th North American Power Symposium, 2006, pp. 325-333.

[40] S. Namitha, J. Cherian, Comparative analysis of deadbeat controller and model predictive controller on DSTATCOM for power quality improvement, Int. J. Sci. Res. 2015, vol. 4, no. 9, pp. 1012-1019.

[41] H.I. Shaheen, G.I. Rashed, S.J. Cheng, Design of new nonlinear optimal predictive controller for Unified Power Flow Controller, in: 2008 IEEE Power and Energy Society General Meeting - Conversion and Delivery of Electrical Energy in the 21st Century, 2008, pp. 1-10.

[42] H.I. Shaheen, G.I. Rashed, S.J. Cheng, Nonlinear optimal predictive controller for static synchronous compensator (STATCOM), in: 2008 IEEE/PES Transmission and Distribution Conference and Exposition, 2008, pp. $1-7$. 